\title{
Relationship between age and clinical and laboratory features at admission in patients with pulmonary embolism
}

\author{
Boris Džudović ${ }^{1}$, Bojana Subotić ${ }^{1}$, Danijela Vraneš ${ }^{1}$, Milica Stavrić2, Vesna Subota², \\ Milica Mirić ${ }^{3}$, Jovan Matijašević ${ }^{3}$, Sonja Šalinger ${ }^{4}$, Slobodan Obradović ${ }^{1}$ \\ ${ }^{1}$ Clinic of Emergency Internal Medicine, School of Medicine, University of Defence, Military Medical Academy, \\ Belgrade, Serbia, ${ }^{2}$ Institute for Medical Biochemistry, School of Medicine, University of Defence, Military Medical \\ Academy, Belgrade, Serbia, ${ }^{3}$ Institute of Pulmonary Medicine, Sremska Kamenica, Vojvodina, Serbia, ${ }^{4}$ Clinic of \\ Cardiology, Clinical Center Nis, School of Medicine, University Nis, Serbia
}

Abstract Objective. The relation between age and clinical presentation of pulmonary embolism (PE) is not investigated in details.

Methods. One hundred and seventy two consecutive patients with PE treated in the period of five years in the single center were enrolled in this study. According to age, patients were divided into tertiles, I $\leq 54$ years, II 54-70 years and III $>70$ years. Patients' characteristics, Wells score, risk distribution, basic symptoms, ECG signs, laboratory markers at admission and six-month outcome were compared between tertiles of age.

Results. Patients in the third tertile were more often women, and had suffered more from common comorbidities. In the first tertile males and smokers predominated; patients had lower BMI and more frequently positive family history for venous thromboembolism. In the third tertile of age fewer patients were presented as a high probability Wells score and more patients could be classified as high-risk patients. Among ECG signs in the multivariant analysis only atrial fibrillation were significantly associated with advance age. Admission glycaemia, brain natriuretic peptide and ddimers significantly increased and arterial oxygen pressure decreased across the tertiles no matter the presence of comorbidities which may have strong influence. The overall six-month mortality and major bleeding were not significantly different across the tertiles in whole group, but if we excluded patients with malignant disease, mortality rate was highest in the third tertile of age.

Conclusion. In patients with PE there are several important differences in clinical presentation of PE which may have important influence on diagnostic procedures, therapy and outcome.

Key Words age, electrocardiography, pulmonary embolism, symptoms

\section{Introduction}

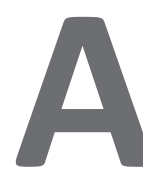

ge is one of the most important features of patients which modulate etiology, clinical characteristics, symptoms, laboratory markers and outcome of almost every disease. In patients with pulmonary embolism the influence of age could be even more pronounced. Hereditary thrombophilias, pregnancy, puerperium, oral contraceptives and trauma are the most often causes of pulmonary embolism in younger patients, however, malignancy, surgery, neurologic diseases and immobilization are the leading causes of the disease in elderly $1-5$. Since clinical picture of pulmonary embolism very much depends on the cardiorespiratory status it is very likely that symptoms and signs of disease are quite different in elderly compared to younger patients ${ }^{4}$. The differences in the clinical presen- tation of PE in elderly may aggravate and deceive the diagnostic algorithm and make several procedures less sensitive and specific. Chronic diseases add very much to the severity and worsen outcome of PE in older patients. Several comorbidities also may have very strong influence to the susceptibility of bleeding, like previous stroke, ulcer disease and chronic renal failure which are very common in elderly patients $s^{4,6,7}$. Usage of aspirin, other antiplatelet drugs, non-steroid anti-inflammatory drugs and so many others are extremely frequent in older patients and can influence the decision of therapy and risk of bleeding in patients with $\mathrm{PE}^{8,9}$.

We investigated the relationship between age and other clinical and laboratory features of pulmonary embolism at admission. We also examined the possible influence of age on six months mortality and bleeding events in patients with acute pulmonary embolism. 
Table 1. Patient characteristics and treatment according to tertiles of age at admission.

\begin{tabular}{|c|c|c|c|c|c|}
\hline Characteristics & $\begin{array}{c}\text { All } \\
\mathrm{N}=172\end{array}$ & $\begin{array}{l}\leq 54 y \\
N=58\end{array}$ & $\begin{array}{c}>54 \text { y and }<70 y \\
N=56\end{array}$ & $\begin{array}{l}>70 y \\
N=58\end{array}$ & $P$ \\
\hline Female - n, \% & $88,51.2$ & $19,32.8$ & $29,51.8$ & $40,69.0$ & $<0.001$ \\
\hline Spontaneous - n, \% & $83,48.3$ & $28,48.3$ & $22,39.3$ & $33,56.9$ & 0.170 \\
\hline \multicolumn{6}{|l|}{ Risk factors for PE } \\
\hline $\mathrm{BMI}-$ mean $\pm \mathrm{SD} \mathrm{kg} / \mathrm{m}^{2}$ & $27.6 \pm 4.4$ & $26.3 \pm 3.8$ & $28.6 \pm 5.1$ & $28.0 \pm 3.9$ & 0.010 \\
\hline Obesity - BMI>30 kg/m²-n, \% & $39,24.1$ & $11,19.0$ & $17,30.4$ & $14,24.1$ & 0.367 \\
\hline Active smoking $-n, \%$ & $33,20.9$ & $23,39.7$ & $9,16.1$ & $1,1.7$ & $<0.001$ \\
\hline Major surgery in past 6 months $-n, \%$ & $46,26.7$ & $13,22.4$ & $19,33.9$ & $14,24.1$ & 0.328 \\
\hline Major surgery in past 3 weeks $-n, \%$ & $22,12.8$ & $8,13.8$ & $6,10.7$ & $8,13.8$ & 0.852 \\
\hline Signs of DVT $-n, \%$ & $98,57.0$ & $35,60.3$ & $37,66.1$ & $25,44.8$ & 0.059 \\
\hline Malignancy $-n, \%$ & $24,14.0$ & $6,10.3$ & $11,19.6$ & $7,12.1$ & 0.315 \\
\hline Positive familial anamnesis to DVT/PE - n, \% & $20,11.6$ & $13,22.4$ & $4,7.1$ & $3,5.2$ & 0.007 \\
\hline \multicolumn{6}{|l|}{ Comorbidities } \\
\hline Chronic heart failure or chronic obstructive & & & & & \\
\hline pulmonary disease $-\mathrm{n}, \%$ & $33,19.2$ & $7,12.1$ & $7,12.5$ & $19,32.8$ & 0.006 \\
\hline Diabetes type $2-n, \%$ & $22,12.8$ & $3,5.2$ & $7,12.5$ & $12,20.7$ & 0.044 \\
\hline Coronary disease $-n, \%$ & $19,11.0$ & $2,3.4$ & $4,7.1$ & $13,22.4$ & 0.003 \\
\hline Previous stroke $-n, \%$ & $9,5.2$ & $1,1.7$ & $2,3.6$ & $7,12.1$ & 0.040 \\
\hline Previous major bleeding $-n, \%$ & $22,12.8$ & $11,19.0$ & $5,8.9$ & $6,10.3$ & 0.218 \\
\hline Heart rate - mean $\pm S D$ & $102 \pm 22$ & $99 \pm 22$ & $102 \pm 23$ & $105 \pm 21$ & 0.334 \\
\hline Systolic arterial blood pressure $-\mathrm{mmHg}$ mean $\pm \mathrm{SD}$ & $120 \pm 28$ & $122 \pm 23$ & $122 \pm 24$ & $116 \pm 34$ & 0.413 \\
\hline \multicolumn{6}{|l|}{ Wells score } \\
\hline$<5$ & $85,52.5$ & $32,55.2$ & $21,37.5$ & $38,65.5$ & 0.010 \\
\hline$\geq 5$ & $77,47.5$ & $26,44.8$ & $35,62.5$ & $20,34.5$ & \\
\hline \multicolumn{6}{|l|}{ sPESI - n, \% } \\
\hline 0 & $56,31.4$ & $28,48.3$ & $19,33.9$ & $7,12.1$ & $<0.001$ \\
\hline $1-2$ & $82,47.7$ & $26,44.8$ & $29,51.8$ & $27,46.6$ & \\
\hline$\geq 3$ & $36,20.9$ & $4,6.9$ & $8,14.3$ & $24,41.4$ & \\
\hline \multicolumn{6}{|l|}{ Risk score $-n, \%$} \\
\hline Low & $56,32.6$ & $29,50.0$ & $11,19.6$ & $16,27.6$ & $<0.001$ \\
\hline Intermediate & $90,52.3$ & $24,41.4$ & $39,69.6$ & $27,46.6$ & \\
\hline High & $26,15.1$ & $5,8.6$ & $6,10.7$ & $15,25.9$ & \\
\hline Thrombolytic therapy & $100,58.1$ & $28,48.3$ & $34,60.7$ & $34,58.6$ & 0.356 \\
\hline \multicolumn{6}{|l|}{ Oral anticoagulant therapy } \\
\hline Vitamin $\mathrm{K}$ antagonists & $63,36.6$ & $23,36.5$ & $20,41.7$ & $20,39.2$ & 0.956 \\
\hline Direct oral anticoagulants & $91,52.9$ & $32,58.2$ & $28,58.3$ & $31,60.8$ & \\
\hline
\end{tabular}

\section{Methods}

One hundred and seventy two consecutive patients diagnosed and treated for PE in the period from January 2010 to November 2015 in the Clinic of Emergency Internal Medicine at Military Medical Academy in Belgrade are enrolled in the study. All patients had confirmed PE at multidetector computed pulmonary angiography. Cohort of patients is split into three groups according to tertiles of age. The first tertile is presented with patients at 54 years old or younger, the second tertile is between 54 and 69 years old and the third tertile represents patients who are 70 years old or older. The main characteristics of patients were registered at admission including gender, possible cause of PE, risk factors (body mass index, active smoking, symptomatic deep vein thrombosis, positive family history of venous thromboembolism, presence of malignant disease and recent surgery) and comorbidities (the presence or the positive history of chronic heart failure, chronic obstructive pulmonary disease, diabetes mellitus, coronary disease, stroke and major non traumatic bleeding events). According to European Society of Cardiology guidelines patients were classified into 3 risk groups (low-risk - normotensive patients without signs of right ventricle dysfunction, inter- mediate-risk - normotensive patients with signs of right ventricle dysfunction and high-risk - hypotensive patients due to PE) ${ }^{10}$. According to Well's score patients were belonged to low-probability PE group (Wells $<5$ ) and high probability group (Well' score $\geq 5$ ) ${ }^{11}$. Simplified Pulmonary Embolism Score Index were calculated with admission parameters and patients were also divided into 3 groups (low risk - sPESI 0, intermediate $-1-2$ and high risk with SPESI 3 and more) ${ }^{12}$. The presence of the most characteristic symptoms of PTE was noted at admission (acute dyspnea, chest pain, syncope, hemoptysis, fever). The typical ECG signs were also verified at admission ECG recording (S1Q3T3 sign, complete or incomplete right bundle branch block, negative T waves in precordial leads, S wave in aVL and atrial fibrillation or flutter). .

\section{Laboratory markers}

Admission glycaemia was determined from the venous blood sample collected at admission and it was measured immediately by using commercial Dimension clinical chemistry system.

D-dimer was measured from the venous sample taken into the citrated tubes at admission (DADE Behring $\mathrm{BCS} X \mathrm{XP})$. . 
Table 2. Symptoms at presentation and ECG signs in PE patients according to tertiles of age.

\begin{tabular}{|c|c|c|c|c|c|c|}
\hline Symptoms and ECG signs & $\begin{array}{l}\leq 54 y \\
N=58\end{array}$ & $\begin{array}{c}>54 \text { and } \leq 70 \\
N=56\end{array}$ & $\begin{array}{l}>70 \\
N=58\end{array}$ & $\mathrm{p}$ & $\begin{array}{l}\text { OR }(96 \% \mathrm{CI}) \\
\text { III vs I tertile }\end{array}$ & $\begin{array}{c}\text { Adjusted }^{1} \text { OR }(95 \% \mathrm{Cl}) \\
\text { III vs I tertile }\end{array}$ \\
\hline \multicolumn{7}{|l|}{ Symptoms - n, \% } \\
\hline Dispnea & $50,86.2$ & $50,89.3$ & $54,93.1$ & 0.478 & $2.16(0.61-7.61)$ & $1.39(0.37-5.22)$ \\
\hline Haemoptysis & $9,15.5$ & $6,10.7$ & $3,5.2$ & 0.190 & $0.30(0.08-1.16)$ & $0.35(0.08-1.52)$ \\
\hline Syncope & $3,5.2$ & $12,21.4$ & $11,19.0$ & 0.032 & 4.29 (1.13-16.30) & 2.47 (0.59-10.29) \\
\hline Chest pain & $26,44.8$ & $21,37.5$ & $10,17.2$ & 0.005 & $0.26(0.11-0.60)$ & $0.40(0.15-1.07)$ \\
\hline Febrile state & $22,37.9$ & $12,21.4$ & $11,19.0$ & 0.042 & $0.38(0.16-0.89)$ & $0.51(0.19-1.33)$ \\
\hline Severe pneumonia & $19,32.8$ & $7,12.5$ & $2,3.4$ & $<0.001$ & $0.07(0.02-0.33)$ & $0.05(0.01-0.31)$ \\
\hline \multicolumn{7}{|l|}{ ECG signs $-n, \%$} \\
\hline S1Q3T3 pattern on admission & $11,19.0$ & $18,32.1$ & $17,29.3$ & 0.244 & $1.72(0.74-4.21)$ & $1.27(0.46-3.51)$ \\
\hline RBBB on admission & $9,15.5$ & $15,28.8$ & $18,31.0$ & 0.133 & $2.45(0.99-6.04)$ & $1.23(0.42-3.61)$ \\
\hline T wave inversion on admission & $18,31.0$ & $28,50.0$ & $33,56.9$ & 0.015 & $2.93(1.37-6.28)$ & $2.07(0.83-5.14)$ \\
\hline S pattern in AVL on admission & $27,46.6$ & $30,53.6$ & $27,46.6$ & 0.689 & $1.00(0.48-2.07)$ & $0,65(0.25-1.66)$ \\
\hline Atrial fibrillation & $1,1.7$ & $7,12.5$ & $19,32.8$ & $<0.001$ & $27.77(3.57-216.08)$ & $21.93(2.58-186.37)$ \\
\hline
\end{tabular}

${ }^{1}$ Adjusted to gender, the presence of chronic heart failure or chronic obstructive disease and risk score.

Partial oxygen pressure was determined from the arterial heparinized blood sample using commercials cartridges (Instrumental Laboratory, GEM Premier 3000).

B-type natriuretic peptide was determined in plasma samples at the first morning after hospitalization on commercial ADVIA Centaur analyzer (Siemens Medical Solutions, Fernwald, Germany) using direct chemiluminescence immunoassay.

\section{Follow-up and survival analysis}

Patients were scheduled for visits after one and 6 months. Kaplan Meyer analysis and log rank test were used for the comparison of 6-months mortality. Major bleeding was defined as International Society of Thrombosis and Hemostasis definition.

\section{Statistics}

Patient characteristics, symptoms and ECG signs were presented as numbers and frequencies and age as mean \pm SD. Since the values of admission glycaemia, oxygen arterial pressure, BNP and D-dimer hadn't normal distribution comparison between tertiles of age was estimated with Mann-Whitney test. Univariate binary logistic regression and binary regression adjusted to the strongest confounding factors (gender, the presence of chronic obstructive pulmonary and chronic heart failure and the European risk score) was used to determine odds ratio between third and first tertile of age for various symptoms and ECG signs at presentation. The blood concentrations of admission d-dimer, glycaemia and arterial oxygen partial pressure, and brain natriuretic peptide (BNP) and C-reactive protein (CRP) at the first hospitalization day in the whole group and in the subgroups of patients in whom the most important confounding characteristics were exclude, were compared across the tertiles of age with Kruskal-Wallis test. Kaplan-Meyer analysis and log-rank test was used to compare 6-months mortality and major bleeding in all patient cohort and in cohort of patients without patients with malignant disease. $P$ value less than 0.05 was considered significant.

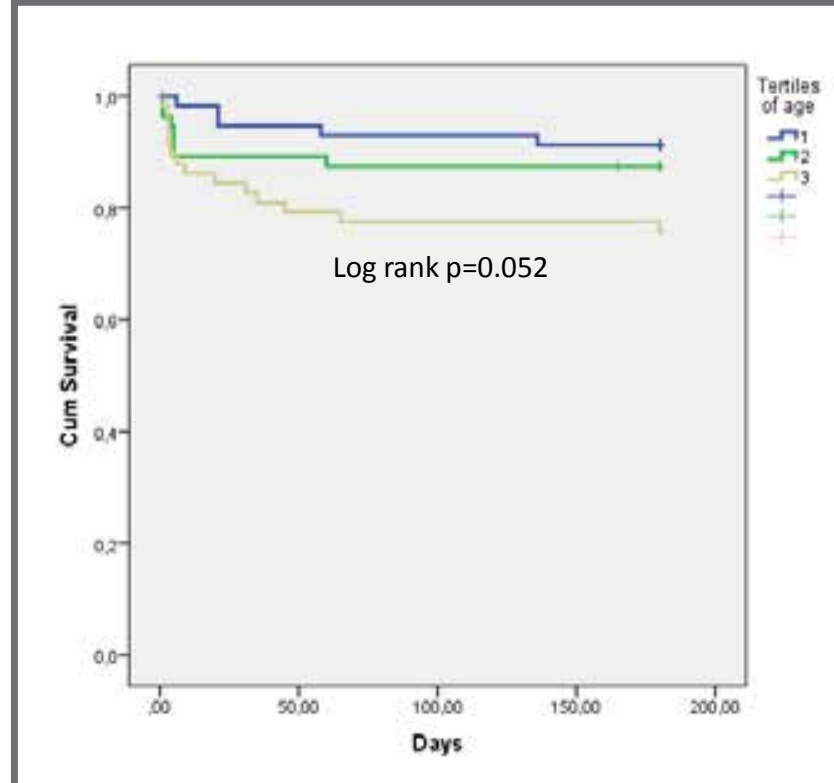

Figure 1A. 6-month cumulative survival in all patients.

\section{Results}

Patient characteristics are presented in table 1 . The distribution of genders is asymmetric across the tertiles of age. Men predominate in the first tertile and women in the third. Similar number of patients has spontaneous or provoked PE. Younger patients were more often active smokers, they had lower BMI, and more often presented with symptoms of deep vein thrombosis and had positive family history of vein thrombosis. All comorbidities were more frequently presented in the third tertiles of patients. Patients in the first tertile had higher proportion of high probability Well's score than the patients in the third tertile. Finely, older patients were more often presented with higher SPESI and with high risk features at admission. There was no significant difference between the thrombolytic and oral anticoagulant treatment through the age tertiles.

The main symptoms were also differently distributed across age (table 2). Younger patients had more often chest pain and pneumonia and older patients had syn- 
Table 3. Frequently used biomarkers at presentation according to tertiles of age.

\begin{tabular}{|c|c|c|c|c|}
\hline Biomarkers & $\begin{array}{l}\leq 54 y \\
N=58\end{array}$ & $\begin{array}{c}>54 \text { and } \leq 70 \\
N=56\end{array}$ & $\begin{array}{c}>70 \\
N=58\end{array}$ & $P$ \\
\hline \multicolumn{5}{|l|}{ Admission D-dimer (mg/L) } \\
\hline All patients & $5.77(2.20-12.92)$ & 9.35 (3.73-20.69) & $11.27(6.55-22.10)$ & 0.007 \\
\hline Without patients with cancer & $5.10(2.29-12.40)$ & $8.71(3.15-17.00)$ & $10.90(6.69-22.00)$ & 0.025 \\
\hline \multicolumn{5}{|l|}{ First day BNP (pg/ml) } \\
\hline All patients & $56.20(15.00-128.07)$ & $119.75(52.25-228.25)$ & $341.00(138.05-677.41)$ & $<0.001$ \\
\hline Without patients with $\mathrm{CHF}$ & $53.70(13.50-112.00)$ & $119.75(52.25-223.27)$ & $221.00(112.00-484.00)$ & $<0.001$ \\
\hline Without patients with stage IV and V CKF & $56.00(15.00-125.05)$ & $119.75(46.75-234.75)$ & $267.60(109.50-609.00)$ & $<0.001$ \\
\hline \multicolumn{5}{|l|}{ Admission arterial pO2 (mmHg) } \\
\hline All patients & $77.50(63.50-85.00)$ & $65.00(55.00-80.00)$ & $54.00(48.50-79.50)$ & 0.001 \\
\hline Without patients with CHF or COPD & $77.00(66.50-80.00)$ & $66.50(55.25-80.75)$ & $66.50(49.00-80.50)$ & 0.026 \\
\hline \multicolumn{5}{|l|}{ Admission glycaemia (mmol/L) } \\
\hline All patients & $6.00(5.37-7.12)$ & $7.25(6.20-9.50)$ & $8.70(6.97-11.12)$ & $<0.001$ \\
\hline Without patients with diabetes & $5.80(5.30-7.10)$ & $7.20(6.10-9.15)$ & $8.05(6.52-10.25)$ & $<0.001$ \\
\hline \multicolumn{5}{|l|}{ First day CRP (mg/L) } \\
\hline All patients & $44.80(19.29-74.25)$ & $63.15(27.55-129.75)$ & $59.00(22.31-127.00)$ & 0.151 \\
\hline Without patients with pneumonia & $37.20(16.50-58-00)$ & $60.00(24.00-124.00)$ & $59.00(21.60-125.00)$ & 0.045 \\
\hline
\end{tabular}

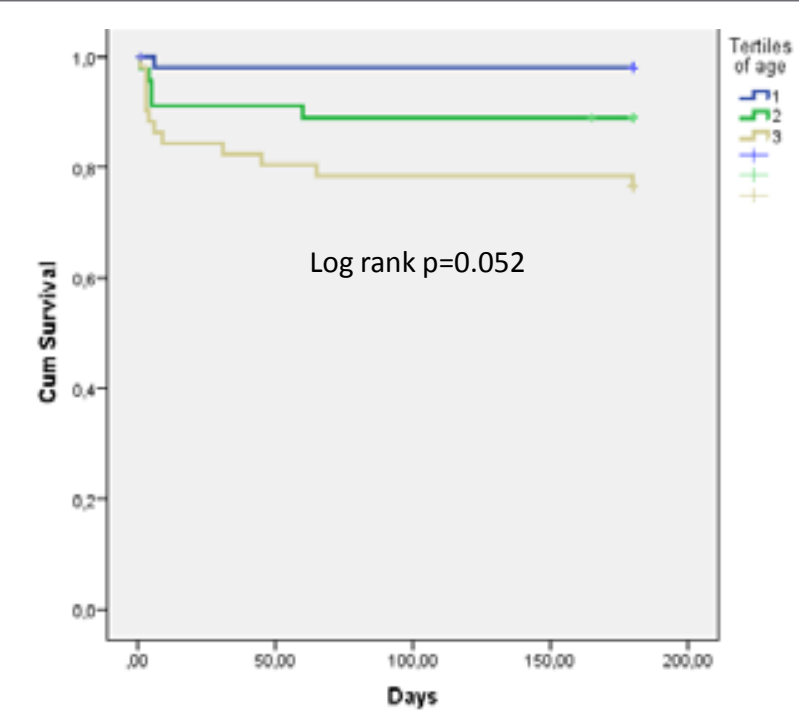

Figure 1B. 6-month cumulative survival without patients with malignant disease.

cope attack. However, when the odds ratio between III and I tertile is adjusted to gender, only the presence of pneumonia in younger patients remain significantly different. Among ECG signs, negative T waves and atrial fibrillation were presented more frequently in older patients. Gender did not influence on ECG signs across the age tertiles.

Some important laboratory admission parameters were significantly different crosswise the tertiles of age. There were gradual decrease of arterial partial oxygen pressure (figure 1) and also gradual increase of the concentration of blood admission glycaemia (figure 2), BNP (figure 3) and D-dimer (figure 4) at every tertile of age.

When we analyzed Kaplan Meyer curves (figure 5A) of 6-month survival in there were no significant difference across the tertiles of age. The frequency of major bleeding episodes was similar in all three tertiles of age (figure 5B).

The causes of death are presented in table 3. Only one patient in the first tertile of age died from pulmo-

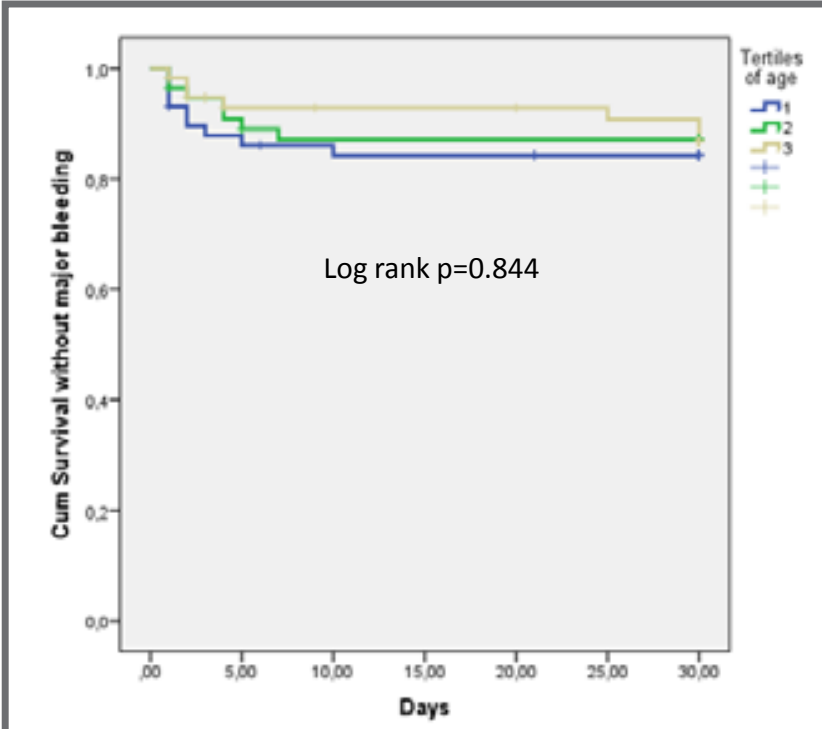

Figure 1C. 6-month cumulative survival without major bleeding.

nary embolism and one died from fatal bleeding. The majority of patients who died in the first tertile died from other causes. On the other side, the proportion of patients who died from PE increase with tertiles of age and equal number of patients died from PE and other causes (both $9.3 \%$ ) in this tertile.

\section{Discussion}

This study has found a lot of differences between patient characteristics, clinical and ECG presentations of PE, as well as in laboratory findings at admission across the tertiles of age. In our study we found asymmetry in gender distribution through the tertiles of age, with the majority of women in the third tertile and majority of men in the first tertile. This finding was also presented by several authors and very probably is caused by the different risk factors in various age population for pulmonary embolism between genders, especially the higher prevalence of obesity in females in elderly ${ }^{13,14}$. Although 
younger patients had lower $\mathrm{BMI}$, we found equal proportion of obese patients in all three tertiles of age. Symptomatic deep vein thrombosis was accompanied to $\mathrm{PE}$ frequently in younger patients. The similar result was described by Sakuma et al in Japanese cohort of deep vein thrombosis and pulmonary embolism patients ${ }^{15}$. This fact describes difficulties in the diagnosis of PE in older patients with less frequently appearance of deep vein thrombosis symptoms in this population of patients. It was expected that younger patients had stronger influence of hereditability which was confirmed by higher percentage of positive family history in younger patients in our study ${ }^{16}$. Several important comorbidities are more common in older patients ${ }^{17}$. We have found higher frequency of diabetes type 2 , coronary disease and history of stroke in the third tertile of our PE cohort.

Wells rule is simple diagnostic score which is recommended for the initial evaluation of patients with suspected PE (ESC Guidelines 2014) ${ }^{10,11}$. In our study group of diagnosed PE patients this score has shown that lower proportion of patients in the third tertile of age had high probability score. It seems that Wells score has not the same predictive value for the diagnosis of PE in elderly patients ${ }^{18}$. Since patients with advance age have decrease cardiopulmonary reserve it is expected that they are presented with high-risk features. Several recently published papers, as our present study, have shown that older age are associated with severe PE clinical picture at presentation ${ }^{13,19}$.

Presenting symptoms of PE was also partly different between older and younger patients in our study. Like some other authors we found less frequently chest pain and more frequently syncope in older patients ${ }^{20,21}$.

We have chosen four admission laboratory parameters to compare between tertiles of age. Several biochemical markers are used as surrogates to main pathophysiology processes in $\mathrm{PE}$, partial pressure of oxygen is surrogate for respiratory-cardiovascular function, admission glycaemia for stress reaction, BNP for heart failure and finely D-dimer is an important bio-chemical marker of intravascular thrombosis and well established marker of the disease (ESC 2014) and probably weak prognostic marker ${ }^{21-24}$. We have found that all these markers significantly and gradually increase through the tertiles of age.

Mortality in patients with PE can be caused by the PE itself, but the influence of comorbidities is huge and the overall mortality rate is much higher than the mortality from PE. Bleeding complications can also contribute or even be the main reason to death. Several large registries have shown very different mortality rate from $5.4 \%$ to $20.0 \%$ during the first 30 days ${ }^{25-29}$. However, the age was one of the most important risk factors for death in PE. In our study 9 (5.5\%) patients died from PE, 14 (8.6\%) died from various other causes and 2 (1.2\%) patients died because of fatal bleeding. Since the fact that patients with PE in our study were admitted to intensive care unit, our cohort of PE patients does not represent the whole population of PE patients, rather more severe cases who need, at least for short period of time, intensive care. PE as a cause of death rises from the first to the third tertile of age in our group. Other causes, (ma- jority of them were infections, arterial vascular accidences and malignant diseases) were the causes of deaths more frequently than $P E$, especially in the younger patients. Like in our study, large Danish population based cohort study (30) has shown that more than $50 \%$ of patients died from other reasons apart from PE.

Conclusions. There are several important differences in the patient characteristics, symptoms at presentation, ECG signs, and risk scores in patients with PE depending on age.

Conflict of interests: The authors have no conflict of interests to disclose.

\section{References}

1. Zöller B, Li X, Sundquist J, Sundquist K. Age- and gender-specific familial risks for venous thromboembolism: a nationwide epidemiological study based on hospitalizations in Sweden. Circulation. 2011;124(9):1012-20.

2. Tsai J, Grosse SD, Grant AM, Reyes NL, Hooper WC, Atrash HK. Correlates of in-hospital deaths among hospitalizations with pulmonary embolism: findings from the 2001-2008 National Hospital Discharge Survey. PLoS One. 2012;7(7):e34048.

3. Nauffal D, Ballester $M$, Reyes RL, Jiménez D, Otero R, Quintavalla $R$, Monreal M. RIETE Investigators. Influence of recent immobilization and recent surgery on mortality in patients with pulmonary embolism. J Thromb Haemost. 2012;10(9):1752-60.

4. Le Gal G, Righini M, Roy PM, Meyer G, Aujesky D, Perrier A, Bounameaux $H$. Differential value of risk factors and clinical signs for diagnosing pulmonary embolism according to age. J Thromb Haemost. 2005;3(11):2457-64.

5. Eichinger S, Evers JL, Glasier A. Venous thromboembolism in women: a specific reproductive health risk. Hum Reprod Update. 2013;19(5):471-82.

6. Cefalo P, Weinberg I, Hawkins BM, Hariharan P, Okechukwu I, Parry BA, Chang Y, Rosovsky R, Liu SW, Jaff MR, Kabrhel C. A comparison of patients diagnosed with pulmonary embolism who are $\geq 65$ years with patients $<65$ years. Am J Cardiology. 2015;115(5):681-6.

7. Zhang NF, Zhou YM, Yang XY, Tang CL, Wu H, Zhong NS. Clinical characteristics and prognostic factors of pulmonary embolism in different age groups. Zhonghua Jie $\mathrm{He} \mathrm{He} \mathrm{Hu} X \mathrm{Xi} Z \mathrm{Za} Z$ hi. 2010;33(6):436-40.

8. Majeed A, Goldhaber SZ, Kakkar A, Kearon C, Eriksson H, Kreuzer J, Feuring M, Hantel S, Friedman J, Schellong S, Schulman S. Bleeding events with dabigatran or warfarin in patients with venous thromboembolism. Thromb Haemost. 2015;115(2).

9. Di Nisio M, Ageno W, Rutjes AW, Pap AF, Büller HR. Risk of major bleeding in patients with venous thromboembolism treated with rivaroxaban or with heparin and vitamin $\mathrm{K}$ antagonists. Thromb Haemost. 2015;115(2).

10. Konstantinides SV, Torbicki A, Agnelli G, Danchin N, Fitzmaurice D, Galiè N, Gibbs JS, Huisman MV, Humbert M, Kucher N, Lang I, Lankeit M, Lekakis J, Maack C, Mayer E, Meneveau N, Perrier A, Pruszczyk P, Rasmussen LH, Schindler TH, Svitil P, Vonk Noordegraaf A, Zamorano JL, Zompatori M. 2014 ESC guidelines on the diagnosis and management of acute pulmonary embolism. Eur Heart J 2014; 35(43):3030-80.

11. Wells PS, Anderson DR, Rodger M, Stiell I, Dreyer JF, Barnes D, Forgie M, Kovacs G, Ward J, Kovacs MJ.. Excluding pulmonary embolism at the bedside without diagnostic imaging: management of patients with suspected pulmonary embolism presenting to the emergency department by using a simple clinical model and d-dimer. Ann Intern Med 2001;135(2):98-107.

12. Righini M, Roy PM, Meyer G, Verschuren F, Aujesky D, Le Gal G. The Simplified Pulmonary Embolism Severity Index (PESI): validation of a clinical prognostic model for pulmonary embolism. J Thromb Haemost 2011;9(10):2115-7.

13. Keller K, Beule J, Coldewey M, Dippold W, Balzer JO. Impact of advanced age on the severity of normotensive pulmonary embolism. Heart Vessels. $2015 ; 30(5): 647-56$. 
14. Obradovic S, Dzudovic B, Rusovic S, Subota V, Obradovic D. Gender related differences inclinical presentation, electrocardiography signs, laboratory markers and outcome in patients with acute pulmonary embolism. Vojnosanit Pregl First Online 2015.

15. Sakuma M, Nakamura M, Yamada N, Ota S, Shirato K, Nakano T, Ito $M$, Kobayashi T. Deep vein thrombosis with pulmonary embolism, deep vein thrombosis alone, and pulmonary embolism alone. Circ J. 2009;73:305-9.

16. Zöller B, Li X, Ohlsson H, Ji J,Sundquist J, Sundquist K. Family history of venous thromboembolism as risk factor and genetic research tool. Thromb Haemost. 2015;114(5):890-900.

17. Castelli R, Bucciarelli P, Porro F, Depetri F, Cugno M. Pulmonary embolism in elderly patients: prognostic impact of the Cumulative Illness Rating Scale (CIRS) on short-term mortality. Thromb Res. 2014; 134: 326-30.

18. Schouten HJ, Geersing GJ, Oudega R, van Delden JJ, Moons KG, Koek HL. Accuracy of the Wells clinical prediction rule for pulmonary embolism in older ambulatory adults. J Am Geriatr Soc. 2014;62(11):2136-41.

19. Zhang NF, Zhou YM, Yang XY, Tang CL, Wu H, Zhong NS. Clinical characteristics and prognostic factors of pulmonary embolism in different age groups. Zhonghua Jie He He Hu Xi Za Zhi. 2010;33(6):436-40.

20. Kokturk N, Oguzulgen K, Demir N, Demirel K, Ekim N. Differences in clinical presentation of pulmonary embolism in older vs younger patients. Circ J. 2005;69:981-6.

21. Punukollu, H, Khan IA, Punikollu G, Gowda RM, Mendoza C, Sacchi TJ. Acute pulmonary embolism in elderly: clinical characteristics and outcome. Int J Cardiol. 2005;99:213-6.
22. Scherz N, Labarere J, Aujesku D, Neab M. Elevated admission glucose and mortality in patients with acute pulmonary embolism. Diabetes Care. 2012;35:25-31.

23. Coutance G, Le Page O, Lo T, Hamon M. Prognostic value of brain natriuretic peptide in acute pulmonary embolism. Critical Care. 2008;12(4):R109.

24. Gong X, Duan Z, Yuan Y. Long-term prognosis and related factors towards patients with acute pulmonary embolism. Int J Clin Exp Med. 2015;8(5):7906-13.

25. Torbicki A, Galié N, Covezzoli A, Rossi E, De Rosa M, Goldhaber SZ; ICOPER Study Group. Right heart thrombi in pulmonary embolism:results from the International Cooperative Pulmonary Embolism Registry. J Am Coll Cardiol. 2003;41(12):2245-51.

26. Laporte $S$, Mismetti P, Décousus $H$, et al. RIETE Investigators. Clinical predictors for fatal pulmonary embolism in $15,520 \mathrm{pa}-$ tients with venous thromboembolism; findings from the Registro Informatizado de la Enfermedad Trombo Embolica venosa (RIETE) Registry. Circulation 2008 1;117(13):1711-6.

27. Pollack CV, Schreiber D, Goldhaber SZ, et al. Clinical characteristics, management, and outcomes of patients diagnosed with acute pulmonary embolismin the emergency department: initial report of EMPEROR (Multicentar Emergency Medicine Pulmonary Embolism in the Real World registry). J Am Coll Cardiol. 2011;57(6):700-6.

28. Venetz1 $C$, Jiménez $D$, Méan $M$, Aujesky D. A comparison of the original and simplified Pulmonary Embolism Severity Index. Thromb Haemost. 2011; 106: 423-428.

29. Søgaard KK, Schmidt M, Pedersen L, Horváth-Puhó E, Sørensen HT. 30-Year mortality after venous thromboembolism: a population-based cohort study. Circulation. 2014;130:829-36. 